\title{
Difficult Laparoscopic Cholecystectomy
}

\author{
Mohammed Alabed Alhamid ${ }^{1}$ \\ ${ }^{1}$ Department of General Surgery, King Fahad Hospital, Albaha, Saudi Arabia \\ Correspondence: Mohammed Alabed Alhamid, Department of General Surgery, King Fahad Hospital, Albaha, \\ Saudi Arabia.
}

Received: May 8, 2019 Accepted: July 5, 2019 Online Published: July 22, 2019

doi:10.5539/gjhs.v11n9p102 URL: https://doi.org/10.5539/gjhs.v11n9p102

\begin{abstract}
Laparoscopic cholecystectomy is as much easy procedure as difficult one. Surgeon should consider every case as his first one. Intraoperative complications are common while transformation to open surgery should be always in consideration. Transformation to open cholecystectomy isn't a sign of lack of experience, rather it is a proof of surgeon cleverness and an evidence of professional competence as it could keep our patient away from life-threatening complications in difficult situations.

Predictive factors for difficulty vary from male patient, repeated acute attacks, history of obstructive jaundice, presence of abnormal anatomical or pathological findings, and adhesions.

The aim of this study was to assess some preoperative causes namely by history, clinical examination and, radiological data which can dependably anticipate the odds of troublesome laparoscopic Cholecystectomy or alteration to open Cholecystectomy .1005 patients experienced laparoscopic cholecystectomy 171 of them were difficult cases (10.05\%). Transformation rate in our study is within the lower limits and accepted internationally. Dense fibrous adhesion and bleeding are the main causes of transformation. History of acute cholecystitis is separate hazard factor for transformation from laparoscopic to open procedure. Gender and age are also showing increasing rate of transformation.

Results shown bile duct damages may evaded even with nearness of hazard factors as anatomical variations from the of biliary channels, intense cholecystitis, extreme endless fibrosis, affected stones inside Hartmann pocket, and short cystic pipe during laparoscopic cholecystectomy by careful watching and wise decision of transformation whenever surgeon feels risk of major complication in case of proceeding in laparoscopic technique.

Mortality not encountered directly through the procedure or in short post-operative period but as sequel of complicated cases. Authors proposes that change of the laparoscopic cholecystectomy isn't really a disappointment of the specialist, as usually explained, yet is a lifesaving method as delineated by the results of the study. The experience of the operating surgeon assumes an essential function on this subject.
\end{abstract}

Keywords: difficult, laparoscopic, cholecystectomy

\section{Introduction}

Minimal invasive surgery brings a revolutionary change in the treatment of patients with gallbladder stones. Laparoscopic cholecystectomy is the procedure of choice for chronic calcular cholecystitis (Zaman, Imaduddin, \& Razzak, 2015).

Mouret introduced laparoscopic cholecystectomy in 1987. It has rapidly replaced open cholecystectomy as the standard treatment and considered The Gold standard treatment for symptomatic gallstone disease (Rexhep et al., 2013) since then minimal invasive surgery still evolving. (Zaman et al., 2015)

Laparoscopic cholecystectomy showed higher benefits for patients with lower prevalence of postoperative complications, feeding earlier, shorter mean hospital stay and equivalent cost compared with open cholecystectomy It has rapidly replaced open cholecystectomy as the standard treatment (Medeiros et al., 2012). There are several definitive advantages of laparoscopic cholecystectomy includes reduced hospitalization, decreased morbidity, short recovery time, and better cosmoses (Deitch, 1981).

Gallstone disease prevalence in general population is $3 \%-20 \%$ of the total population worldwide (Medeiros et al., 2012). Nowadays Laparoscopic Cholecystectomy (LC) is the standard procedure for the treatment of symptomatic gallbladder stones (Ralls et al., 1881). Although few requires transformation to open cholecystectomy (Faust et al., 
1994).

Based on radiological findings, surgeons can select the cases appropriate for their skills aiming at reducing operative complications and minimizing the waste of operating time available (Dubois et al., 1990).

Ultrasound is the modality of choice for measuring gall bladder wall thickness as it is economical, easily available and non-invasive with accuracy of $92 \%$ (Zaman et al., 2015).

During laparoscopic cholecystectomy (LC), the surgeon may encounter difficult situations in which the procedure fails to progress, with a major risk of injuring the major biliary passages because of loss of anatomical details particularly in the triangle of Calot (Kassem et al., 2015).

Patients with long-standing disease and previous bouts of cholecystitis or pancreatitis are at higher risk of experiencing a difficult procedure or transformation and may be at increased risk of bile duct injury or injury to the adjoining viscera (Martin et al., 1995).

Preoperative information of possible intra-operative complications such as uncontrollable bleeding or unclear anatomy, transformation to open surgery will give an extra benefit. (Murayama \& Thompson, 1996) It can be helpful to raise level of cautiousness and establish a criterion that could assess the risk for transformation preoperatively (Hutchinson et al., 1994).

It would be helpful to identify risk of patient's for transformation based on preoperative information can result in more meaningful and accurate preoperative counseling (Daradkeh et al., 1998), improved operating room scheduling and efficiency. Stratification of risk for technical difficulty, and appropriate assignment of resident assistance, may improve patient safety by minimizing time to transformation, and better mental preparation of surgeons and patients (Corr et al., 1994).

In the presence of bile duct stones or gallstone pancreatitis, the standard of care has been ERCP with Endoscopic Sphincterotomy (ES) and stenting. Such patients had treated subsequently with a laparoscopic cholecystectomy to prevent recurrent biliary symptoms and complications. The decision to perform LC depends on the type of presentation of symptoms and the recovery of the patient (Ranjith et al., 2015).

Many authors have shown that change to open cholecystectomy fundamentally extends the time of the 65 procedure and hospital stay and increases complexity. Moreover, from a surgical point of view, a transformation from laparoscopic cholecystectomy to open cholecystectomy can easily be considered as an individual "failure" of the individual surgeon, and supporters of the laparoscopic approach strive to achieve the lowest transformation rate (Taha, 2016).

The aim of our study was to assess some preoperative causes namely by history, clinical examination and, radiological data which can reliably predict the chances of complicated laparoscopic Cholecystectomy or changing to open Cholecystectomy.

In addition, we aimed to report the incidence of most common intraoperative laparoscopic findings e.g. adhesions, frozen Calot's triangle, Mucocele of gallbladder and double cystic duct, and complications e.g. bleeding, injury of CBD, duodenal perforation etc. encountered during laparoscopic Cholecystectomy and how to manage. In addition, we put a spot light on main postoperative complication e.g. bile leakage, jaundice, biliary peritonitis etc. occurred and mentioned their management.

\section{Materials and Methods}

A prospective study, conducted between January 2014 and January 2018 including 1005 patient between the age of 23 to 67 years old of both sexes admitted and treated for gall bladder stones by (LC) in general Surgery Department King Fahad Hospital -Albaha- Kingdom Saudi Arabia.

Inclusion criteria included all the patients had symptomatic cholelithiasis, normal liver function tests (LFT), non-dilated bile ducts, no history of jaundice, age more than 20 years.

Exclusion criteria included patients with concomitant common bile duct (CBD) stones, patients with multiple co-morbidities, patients with disturbed endocrine functions e.g. hypothyroidism and hyperthyroidism, patients with suspected hepatic, pancreatic or biliary malignancy, uncontrolled hypertension. diabetic patients, and patient with relative contraindications for laparoscopy e.g multiple previous upper abdominal explorations.

All Patients underwent normal routine detailed clinical history and investigations like complete hemogram, LFT, Chest X-ray and other repeated preanaesthetic investigations carried out. Abdominal ultrasonography repeated 1 to 2 days prior to the operation. Surgeons who had experience of more than 500 cases of laparoscopic surgery performed the LC. Therefore, the learning curve statistics do not apply to this study. 


\subsection{Methods of Examination}

Every patient was subjected to personal history: as regard name, age, sex, body mass index (BMI), and associated comorbidities. Present history: as regard onset of patient symptoms and progression of treatment plan. History: as regard diabetes mellitus, hypertension, and previous abdominal operations. Full general and local examination. Routine investigations including: Complete blood picture CBC, X-ray chest, ECG, Kidney function test (KFT), Blood sugar level, Liver function tests (LFT), Coagulation profile (PT), Abdominal ultrasonography (US), Computerized axial tomography of the abdomen if indicated, MRCP of the biliary tree if indicated, Hospital admission for acute cholecystectomy or outpatient clinic preparation for elective cases.

Laparoscopic cholecystectomy was proceed by the customary routine four-port technique. The variables we studied included duration of symptoms, period of operation, operative difficulties and, intricacies for example bleeding, biliary wounds, frozen Calot's tringle, adhesions, and, occurrence of transformation to open operation, post-operative obstacles as post-operative infections, post-operative bleeding, and length of hospital stay.

\subsection{Surgical Technique}

A pneumoperitoneum made with a veress needle and automatic inflation of carbon dioxide under $14-\mathrm{mm} \mathrm{Hg}$ pressure. The positioning of trocars varies according to the surgeon's preference. We use 4 trocars.

The first trocar, $10 \mathrm{~mm}$ in diameter, had introduced just above the umbilicus and enables direct visualization. Exploration of the peritoneal cavity should be as thorough as possible. If the laparoscopic operation is feasible based on the appearance of the gall bladder, the other trocars are positioned.

The second trocar, $5 \mathrm{~mm}$ in diameter, had placed in the right subcostal area at the level of umbilicus and in anterior axillary line just for forceps grasps the gall bladder.

The third trocar, $10 \mathrm{~mm}$ in diameter, had placed in the right of midline in xiphisternum area below and to the right of xiphisternum for the instruments, hook, scissors, and clips.

The fourth trocar, $5 \mathrm{~mm}$ in diameter had placed midway between 3rd and 2nd trocars for the forceps that grasps the Hartmann's pouch.

A fifth trocar may be necessary to retract the left lobe of the liver or the omentum in obese patients.

After the trocars are placed, the operation is done like a conventional cholecystectomy, possible pericholecystic adhesions are freed, and the Hartmann's pouch is grasped by forceps to expose the Y-junction. The peritoneum is incised by scissors or a hook on the posterior and then anterior aspect of the pedicle. The cystic duct and artery are isolated under control by Titan clips and sectioned. Then the gallbladder separated progressively from the liver with coagulation of all attached biliary and vascular connections.

The completely freed gallbladder displaced to any point on the abdominal wall for extraction, but the epigastric port usually selected. The gallbladder neck grasped by a strong forceps to expose it entirely or partly. It may be necessary to aspirate the contents of the gallbladder or remove some stones with the forceps to facilitate extraction.

A final examination of the pedicle and the gallbladder bed done with saline lavage when surgeon decide to ensure that there is no bleeding or bile effusion. Subsequently the orifices closed with simple cutaneous sutures after careful emptying of the pneumoperitoneum and local anesthetic infiltration of the wall. As a routine, no drains are left but tube drain fixation left for surgeon dependent decision.

\subsection{Perioperative Care}

Perioperative care generally is minimal. Antibiotic therapy is optional except in acute cholecystitis. Intake of liquids resumes 6 hours after the operation, and the patient begins eating solids the following day. The patient came out on the second or third postoperative day.

\section{Results}

\subsection{Patients}

1005 patients underwent laparoscopic cholecystectomy 851 (84.7\%) were females and 154 (15.3\%) were males with a ratio of 5.7:1 (Table 1). 
Table 1. Gender of the patients

\begin{tabular}{llll}
\hline & Frequency & Percent & Cumulative Percent \\
\hline Female & 851 & 84.7 & 84.7 \\
Male & 154 & 15.3 & 100.0 \\
Total & 1005 & 100.0 & \\
\hline
\end{tabular}

\subsection{AGE Distribution}

According to our work 1005 patient were distributed between 23 years old and 67 years old. They were in different ages as the next table and charts show (Table 2).

Table 2. Age distribution

\begin{tabular}{|c|c|c|c|}
\hline Age & Frequency & Percent & Cumulative Percent \\
\hline 23 & 11 & 1.1 & 1.1 \\
\hline 24 & 28 & 2.8 & 3.9 \\
\hline 25 & 17 & 1.7 & 5.6 \\
\hline 26 & 40 & 4.0 & 9.6 \\
\hline 27 & 51 & 5.1 & 14.6 \\
\hline 28 & 41 & 4.1 & 18.7 \\
\hline 29 & 19 & 1.9 & 20.6 \\
\hline 30 & 12 & 1.2 & 21.8 \\
\hline 31 & 16 & 1.6 & 23.4 \\
\hline 32 & 20 & 2.0 & 25.4 \\
\hline 33 & 11 & 1.1 & 26.5 \\
\hline 34 & 19 & 1.9 & 28.4 \\
\hline 35 & 10 & 1.0 & 29.4 \\
\hline 36 & 26 & 2.6 & 31.9 \\
\hline 37 & 16 & 1.6 & 33.5 \\
\hline 38 & 6 & .6 & 34.1 \\
\hline 39 & 9 & .9 & 35.0 \\
\hline 40 & 25 & 2.5 & 37.5 \\
\hline 41 & 21 & 2.1 & 39.6 \\
\hline 42 & 24 & 2.4 & 42.0 \\
\hline 43 & 43 & 4.3 & 46.3 \\
\hline 44 & 11 & 1.1 & 47.4 \\
\hline 45 & 78 & 7.8 & 55.1 \\
\hline 46 & 28 & 2.8 & 57.9 \\
\hline 47 & 13 & 1.3 & 59.2 \\
\hline 48 & 22 & 2.2 & 61.4 \\
\hline 49 & 25 & 2.5 & 63.9 \\
\hline 50 & 24 & 2.4 & 66.3 \\
\hline 51 & 33 & 3.3 & 69.6 \\
\hline 52 & 42 & 4.2 & 73.7 \\
\hline
\end{tabular}




\begin{tabular}{cccc}
\hline 53 & 3 & .3 & 74.0 \\
54 & 30 & 3.0 & 77.0 \\
55 & 18 & 1.8 & 78.8 \\
56 & 29 & 2.9 & 81.7 \\
57 & 41 & 4.1 & 85.8 \\
58 & 23 & 2.3 & 88.1 \\
59 & 19 & 1.9 & 90.0 \\
60 & 33 & 3.3 & 93.2 \\
61 & 22 & 2.2 & 95.4 \\
62 & 4 & .4 & 95.8 \\
63 & 12 & 1.2 & 97.0 \\
64 & 10 & 1.0 & 98.0 \\
65 & 3 & .3 & 98.3 \\
66 & 7 & .7 & 99.0 \\
67 & 10 & 1.0 & 100.0 \\
Total & 1005 & 100.0 & \\
\hline
\end{tabular}

\subsection{Patient Presentations}

According to number of gallbladder stones patients were either having solitary stone in 118 patient $(11.7 \%)$ and multiple gallbladder stones in 887 patient $(88.3 \%$ ) as showed in the following table and chart (Table 3 ).

Table 3. Presentation of patient

\begin{tabular}{lcccc}
\hline & Frequency & Percent & Valid Percent & Cumulative Percent \\
\hline Solitary & 118 & 11.7 & 11.7 & 11.7 \\
Multiple & 887 & 88.3 & 88.3 & 100.0 \\
Total & 1005 & 100.0 & 100.0 & \\
\hline
\end{tabular}

\subsection{Patient Clinical Presentations}

Based on abdominal ultrasonography, Tenderness in the gall bladder area (right hypochondrium) encountered in $924(91.9 \%)$ patients, while tender palpable gallbladder was present in $58(5.8 \%)$. Twenty-three cases $(2.3 \%)$ had biliary gastritis not responding to medical treatment (Table 4).

Table 4. Main complains of the patients

\begin{tabular}{lcccc}
\hline & Frequency & Percent & Valid Percent & Cumulative Percent \\
\hline Tenderness ( Murphy's sign) & 924 & 91.9 & 91.9 & 91.9 \\
Tender palpable fever & 58 & 5.8 & 5.8 & 97.7 \\
Gastritis & 23 & 2.3 & 2.3 & 100.0 \\
Total & 1005 & 100.0 & 100.0 & \\
\hline
\end{tabular}

\subsection{Rate of Transformation of Laparoscopic to Open Cholecystectomy}

Most patients 962 (95.7\%) completed laparoscopic cholecystectomy, while 43 (4.3\%) patients were converted to open cholecystectomy. (Table 5) 
Table 5. Rate of transformation of laparoscopic to open cholecystectomy

\begin{tabular}{lccc}
\hline & Frequency & Percent & Cumulative Percent \\
\hline Completed & 962 & 95.7 & 95.7 \\
Converted & 43 & 4.3 & 100.0 \\
Total & 1005 & 100.0 & \\
\hline
\end{tabular}

\subsection{Intraoperative Laparoscopic Findings}

Intraoperative laparoscopic findings were accessible GB in 834 patient (83\%), acute cholecystitis with adhesions in 38 patient (3.8\%), Mucocele with adhesions in 29 patient (2.9\%), empyema GB in 29 patient (2.9\%), and small fibrosed GB with adhesions in 23 patient (2.3\%). In addition, the totally frozen Calot's triangle in 17 patient (1.7), choledochal cyst in 12 patient $(1.2 \%)$ and double cystic duct in 23 patient $(2.3 \%)$ as showed in (Table 6$)$.

1005 patients underwent laparoscopic cholecystectomy 171 of them were difficult cases $(10.05 \%)$

Table 6. Intraoperative laparoscopic findings

\begin{tabular}{lccc}
\hline & Frequency & Percent & Cumulative Percent \\
\hline Easy accessible gallbladder & 834 & 83.0 & 83.0 \\
Acute cholecystitis with adhesions & 38 & 3.8 & 86.8 \\
Mucocele with adhesions & 29 & 2.9 & 89.7 \\
Empyema GB & 29 & 2.9 & 92.5 \\
Small fibrosed GB with adhesions & 23 & 2.3 & 94.8 \\
Totally frozen Calot's triangle & 17 & 1.7 & 96.5 \\
Choledochal cyst & 12 & 1.2 & 97.7 \\
Double cystic duct & 23 & 2.3 & 100.0 \\
Total & 1005 & 100.0 & \\
\hline
\end{tabular}

\subsection{Intra-Operative Complications}

In regards to the intra-operative complications, there were 945 patients completed with no complications (94\%). bleeding occurred in 22 cases (2.2\%) bleeding occurred from liver bed in most cases (15 cases) and from cystic artery in minor number of cases (7cases). Usually controlled by compression of liver bed by a gauze or reclipping of the artery, CBD injury in 16 cases (1.6\%), and duodenal perforation in 13 cases $(1.3 \%)$ (Table 7$)$.

Table 7. Intra-operative complications

\begin{tabular}{lccc}
\hline & Frequency & Percent & Cumulative Percent \\
\hline None & 945 & 94.0 & 94.0 \\
Bleeding & 22 & 2.2 & 96.2 \\
CBD injury & 16 & 1.6 & 97.8 \\
Duodenal perforation & 13 & 1.3 & 99.1 \\
Clipping of CBD & 9 & .9 & 100.0 \\
Total & 1005 & 100.0 & \\
\hline
\end{tabular}

\subsection{Post-Operative Complications}

962 patients $(95.7 \%)$ had no post-operative complications. Recognized post-operative complications were bile leakage in 12 cases $(1.2 \%)$ either through drain or by (us) collection postoperative, gallbladder fossa collection in 13 cases $(1.3 \%)$, jaundice in 9 cases $(0.9 \%)$, biliary peritonitis in 3 cases $(0.3 \%)$, and wound infection in 6 cases 
$(0.6 \%)$. (Table 8$)$

Table 8. Post-operative complications

\begin{tabular}{lccc}
\hline & Frequency & Percent & Cumulative Percent \\
\hline Non & 962 & 95.7 & 95.7 \\
Bile leakage & 12 & 1.2 & 96.9 \\
Collection in the gallbladder area & 13 & 1.3 & 98.2 \\
Jaundice & 9 & .9 & 99.1 \\
Biliary peritonitis & 3 & .3 & 99.4 \\
Wound infection & 6 & .6 & 100.0 \\
Total & 1005 & 100.0 & \\
\hline
\end{tabular}

\subsection{Relation Between Intraoperative Laparoscopic Finding and Rate of Transformation}

Relation between intraoperative laparoscopic finding and rate of transformation is tabulated in Table 9, where Intraoperative laparoscopic findings were accessible GB in 834 patient $(83 \%) 7$ cases of total number $(0.83 \%)$ of them were converted to open surgery, acute cholecystitis with adhesions in 38 patient (3.8\%) of total number while 6 cases of them (15.7\%) were converted, Mucocele with adhesions in 29 patient of overall number $(2.9 \%) 3$ cases of them $(10.3 \%)$ were converted, empyema GB in 29 patient of total $(2.9 \%) 6$ cases of them $(20.7 \%)$ were converted, small fibrosed GB with adhesions in 23 patient $(2.3 \%)$ of total number 3 cases of them (13\%) were converted, totally frozen Calot's triangle in 17 patient (1.7) of total, 6 cases of them (35.3\%), choledochal cyst in 12 patient $(1.2 \%)$ of total number, 6 cases of them $(50 \%)$ were converted, and double cystic duct in 23 patient $(2.3 \%)$ of total number, 6 cases of them $(26.1 \%)$ were converted as showed in Table 9.

Table 9. Relation between intraoperative laparoscopic finding and rate of transformation

\begin{tabular}{llll}
\hline & \multicolumn{2}{l}{ Completed laparoscopic } & Total \\
\cline { 2 - 3 } & Completed & Converted & 834 \\
\hline Normal cystic GB & 827 & 7 & 38 \\
Acute cholecystitis with adhesions & 32 & 6 & 29 \\
Mucocele with adhesions & 26 & 3 & 29 \\
Empyema GB & 23 & 6 & 23 \\
Small fibrosed GB with adhesions & 20 & 3 & 17 \\
Totally frozen Calot's triangle & 11 & 6 & 12 \\
Choledochal cyst & 6 & 6 & 23 \\
Double cystic duct & 17 & 6 & 1005 \\
Total & 962 & 43 & \\
\hline
\end{tabular}

\subsection{Relation Between Complication and Rate of Transformation}

Complications in relation to type of cholecystectomy (laparoscopic or open) were non-complicated cases 945 (94\%), 15 case of them converted from laparoscopic to open procedures in percent of $(0.016 \%)$ due to unpredicted technical difficulties or unexpected events.

Sixty cases of total study were complicated intraoperatively, 43 cases of them were converted to open surgery as follow:

Bleeding occurred in 22 cases $(2.2 \%$ of total) and 6 cases of them $(27.2 \%)$ were converted while 16 cases were completed, CBD injury in 16 cases $(1.6 \%$ of total) 6 cases of them $(37.5 \%)$ were converted and 10 was completed laparoscopically, duodenal perforation in 13 cases ( $1.3 \%$ of total) 3 cases of them were completed laparoscopically and 10 cases converted. CBD clipping occurred in nine cases ( $0.9 \%$ of total), 3 cases among them were completed 
laparoscopically after unclipping with no postoperative complication as they has been discovered intraoperatively, while ( 6 cases of the clipped CBD cases were converted to open surgery because unclipping failed). That means rate of transformation increases dramatically in presence of intraoperative complication that discovered intraoperatively. (Table 10)

Table 10. Rate of complications with transformation

\begin{tabular}{lllllll}
\hline \multicolumn{7}{c}{ Intra operative complication and Rate of transformation } \\
\cline { 2 - 7 } & None & Bleeding & CBD injury & Duodenal perforation & Clipping of CBD & Total \\
\hline COMPLETED & 930 & 16 & 10 & 3 & 3 & 962 \\
Converted & 15 & 6 & 6 & 10 & 6 & 43 \\
Total & 945 & 22 & 16 & 13 & 9 & 1005 \\
\hline
\end{tabular}

\subsection{Relation Between Sex and Intraoperative Finding}

AS been tabulated in (Table11) among 834 patients with normal cystic duct 700 were females and 134 were males, also among 38 patients found to have acute cholecystitis with adhesions 29 were female and 9 were males. 29 patients found to have Mucocele with adhesions 25 were females. Also 29 patients found to have empyema of the gallbladder 26 were females and 3 were males. 23 patients had Small fibrosed GB with adhesions all were females, 17 patients had Totally frozen Calot's triangle all were females, 12 had Choledochal cyst all were females and finally 23 patient had double cystic duct 19 were females and 4 were males.

Table 11. Relation between sex and intraoperative finding

\begin{tabular}{|c|c|c|c|c|c|c|c|c|c|c|}
\hline & & \multicolumn{8}{|c|}{ operative finding } & \multirow[b]{2}{*}{ Tota } \\
\hline & & $\begin{array}{l}\text { Normal } \\
\text { cystic } \\
\text { GB }\end{array}$ & $\begin{array}{l}\text { Acute } \\
\text { cholecystitis } \\
\text { with } \\
\text { adhesions }\end{array}$ & $\begin{array}{l}\text { Mucocele } \\
\text { with } \\
\text { adhesions }\end{array}$ & $\begin{array}{l}\text { Empyema } \\
\text { GB }\end{array}$ & $\begin{array}{l}\text { Small } \\
\text { fibrosed } \\
\text { GB with } \\
\text { adhesions }\end{array}$ & $\begin{array}{l}\text { Totally } \\
\text { frozen } \\
\text { Calot's } \\
\text { triangle }\end{array}$ & $\begin{array}{l}\text { Choledochal } \\
\text { cyst }\end{array}$ & $\begin{array}{l}\text { Double } \\
\text { cystic } \\
\text { duct }\end{array}$ & \\
\hline \multirow{2}{*}{$\operatorname{sex}$} & Female & 700 & 29 & 25 & 26 & 23 & 17 & 12 & 19 & 851 \\
\hline & Male & 134 & 9 & 4 & 3 & 0 & 0 & 0 & 4 & 154 \\
\hline Total & & 834 & 38 & 29 & 29 & 23 & 17 & 12 & 23 & 1005 \\
\hline
\end{tabular}

\subsection{Relation Between Sex and Rate of Transformation}

From 851 female patient enrolled in the study 815 cases completed laparoscopic (95.7\%) while in-between 154 male patient 147 (95.4\%) also completed laparoscopically, rate of transformation to open cholecystectomy was $(4.2 \%)$ and $(4.5 \%)$ respectively. (Table 12$)$

Table 12. Relation between sex and rate of transformation

\begin{tabular}{lllll}
\hline & & \multicolumn{2}{l}{ Completion laparoscopic } & \multirow{2}{*}{ Total } \\
\cline { 3 - 5 } & & COMPLETED & Converted & 851 \\
\hline \multirow{2}{*}{ Sex } & Female & 815 & 36 & 154 \\
\hline Total & Male & 147 & 7 & 1005 \\
\hline
\end{tabular}

Statistically significant differences between different variables in the study was found and summarized in Table 13. 
Table 13. Statistical evaluation of different variables in the study

\begin{tabular}{|c|c|c|c|c|c|c|c|c|}
\hline & & $\begin{array}{c}\text { Intra } \\
\text { operative } \\
\text { complication }\end{array}$ & $\begin{array}{l}\text { Postoperative } \\
\text { complication }\end{array}$ & Sex & $\begin{array}{c}\text { Solitary } \\
\text { stone }\end{array}$ & $\begin{array}{c}\text { Main } \\
\text { complain }\end{array}$ & $\begin{array}{l}\text { Operative } \\
\text { finding }\end{array}$ & $\begin{array}{l}\text { Completed } \\
\text { laparoscopic }\end{array}$ \\
\hline \multirow{3}{*}{$\begin{array}{c}\text { Intra } \\
\text { operative } \\
\text { complication }\end{array}$} & $\begin{array}{c}\text { Pearson } \\
\text { Correlation }\end{array}$ & 1 & $.203^{* *}$ & .020 & .033 & $.311^{* *}$ & $.215^{* *}$ & $.570^{* *}$ \\
\hline & $\begin{array}{c}\text { Sig. } \\
(2-\text { tailed })\end{array}$ & & .000 & .518 & .294 & .000 & .000 & .000 \\
\hline & $\mathrm{N}$ & 1005 & 1005 & 1005 & 1005 & 1005 & 1005 & 1005 \\
\hline \multirow{3}{*}{$\begin{array}{l}\text { Postoperative } \\
\text { complication }\end{array}$} & $\begin{array}{c}\text { Pearson } \\
\text { Correlation }\end{array}$ & $.203^{* *}$ & 1 & .032 & .051 & $.130^{* *}$ & $.298^{* *}$ & $.286^{* *}$ \\
\hline & $\begin{array}{c}\text { Sig. } \\
\text { (2-tailed) }\end{array}$ & .000 & & .315 & .103 & .000 & .000 & .000 \\
\hline & $\mathrm{N}$ & 1005 & 1005 & 1005 & 1005 & 1005 & 1005 & 1005 \\
\hline \multirow{3}{*}{ Sex } & $\begin{array}{c}\text { Pearson } \\
\text { Correlation }\end{array}$ & .020 & .032 & 1 & .018 & .060 & $-.066^{*}$ & .006 \\
\hline & $\begin{array}{c}\text { Sig. } \\
\text { (2-tailed) }\end{array}$ & .518 & .315 & & .572 & .058 & .037 & .859 \\
\hline & $\mathrm{N}$ & 1005 & 1005 & 1005 & 1005 & 1005 & 1005 & 1005 \\
\hline \multirow{3}{*}{ Solitary stone } & $\begin{array}{c}\text { Pearson } \\
\text { Correlation }\end{array}$ & .033 & .051 & .018 & 1 & -.048 & .025 & .031 \\
\hline & $\begin{array}{c}\text { Sig. } \\
\text { (2-tailed) }\end{array}$ & .294 & .103 & .572 & & .128 & .426 & .322 \\
\hline & $\mathrm{N}$ & 1005 & 1005 & 1005 & 1005 & 1005 & 1005 & 1005 \\
\hline \multirow{3}{*}{$\begin{array}{c}\text { Main } \\
\text { complain }\end{array}$} & $\begin{array}{c}\text { Pearson } \\
\text { Correlation }\end{array}$ & $.311^{* *}$ & $.130^{* *}$ & .060 & -.048 & 1 & $.089^{* *}$ & $.219^{* *}$ \\
\hline & $\begin{array}{c}\text { Sig. } \\
\text { (2-tailed) }\end{array}$ & .000 & .000 & .058 & .128 & & .005 & .000 \\
\hline & $\mathrm{N}$ & 1005 & 1005 & 1005 & 1005 & 1005 & 1005 & 1005 \\
\hline \multirow{3}{*}{$\begin{array}{l}\text { Operative } \\
\text { finding }\end{array}$} & $\begin{array}{c}\text { Pearson } \\
\text { Correlation }\end{array}$ & $.215^{* *}$ & $.298^{* *}$ & $-.066^{*}$ & .025 & $.089^{* *}$ & 1 & $.395^{* *}$ \\
\hline & $\begin{array}{c}\text { Sig. } \\
\text { (2-tailed) }\end{array}$ & .000 & .000 & .037 & .426 & .005 & & .000 \\
\hline & $\mathrm{N}$ & 1005 & 1005 & 1005 & 1005 & 1005 & 1005 & 1005 \\
\hline \multirow{3}{*}{$\begin{array}{l}\text { Completed } \\
\text { laparoscopic }\end{array}$} & $\begin{array}{c}\text { Pearson } \\
\text { Correlation }\end{array}$ & $.570^{* *}$ & $.286^{* *}$ & .006 & .031 & $.219^{* *}$ & $.395^{* *}$ & 1 \\
\hline & $\begin{array}{c}\text { Sig. } \\
\text { (2-tailed) }\end{array}$ & .000 & .000 & .859 & .322 & .000 & .000 & \\
\hline & $\mathrm{N}$ & 1005 & 1005 & 1005 & 1005 & 1005 & 1005 & 1005 \\
\hline
\end{tabular}

**. Correlation is significant at the 0.01 level (2-tailed).

*. Correlation is significant at the 0.05 level (2-tailed).

\section{Discussion}

Many studies published in literature on predictive factors of difficult laparoscopic cholecystectomy but there is little data on extent of difficulty of laparoscopic Cholecystectomy by history, radiological and clinical examination when ultrasound finding had their limitations. 
The aim of our study was to report the happening of most common intraoperative laparoscopic findings namely adhesions, frozen Calot's triangle, mucocele of gallbladder and double cystic duct, and complications namely bleeding, injury of CBD, duodenal perforation encountered during laparoscopic cholecystectomy and how to manage them. In addition, we put a spotlight on main postoperative complication namely bile leakage, jaundice, biliary peritonitis occurred and mentioned their management.

We compared our results to the latest studied from near countries and the results from most common published studies available.

The mean age of our patients was 37 years, very close result reported by Saeed et al in Yemen (Al-Bahlooli et al., 2009) and close to that of Pervez Iqbal et al. (2013) in Pakistan and India respectively.

In our study, the presence of male sex was less common (15.3\%) in the study but related essentially with trouble in adhesiolysis, and Calot's triangle analyzation.

As regard gender and risk of transformation we found that among 851 female patients enrolled in the study 815 cases completed laparoscopic (95.7\%) while in-between 154 male patient $147(95.4 \%)$ also completed laparoscopically, rate of transformation to open cholecystectomy was (4.2\%) and (4.5\%) respectively. That means no significant difference which does not run with other studies.

Several reports have identified male gender as a risk factor for transformation (Sultan et al., 2013; Lipman M et al., 2007) the exact explanation is not fully known but it may due to the fact that men are more tolerant to pain than women or reluctant or too busy to seek medical advice (Sultan et al., 2013).

According to (Yol et al., 2006) men with symptomatic gall bladder are more prone to inflammation and fibrosis with the same disease intensity thus leading to difficulty in dissection as reflected in our study.

They obtained higher levels of collagen, hydroxyproline, macrophages, mast cells and eosinophils in gallbladder wall and pericholecystic tissue that might explain the male fibro genic propensity.

Russel et al., 1998 have suggested that men tend to present late as they pay less attention to subtle symptoms, therefore, may have more advanced disease.

In a study by Merriam et al. (1999) acute gangrenous cholecystitis was twice more likely to develop in men than in women, and male gender was a recognized factor for complicated cholecystitis. The study considered that these variations might handle the noticeable impact on the outcomes in men. Also in another study, severe gallbladder inflammation (gangrenous and necrotizing cholecystitis) seen in a significant portion of the male population compared to the female population.

The study of Lengyel et al. (2011) mentioned the harmful impacts of change like protracting of the complete operative time, post-usable dismalness and medical clinic costs, yet our point of view is the counteractive action of complications and safety of patients.

The most common cause of transformation in our study was dens adhesion that obscures the anatomy, especially that of Calot's triangle in the following rates.

Acute cholecystitis with adhesions in 38 patients (3.8\%), 6 cases of them (15.7\%) were converted to open surgery. Mucocele with adhesions in 29 patients (2.9\%), 3 cases (10.3\%) of them were converted to open surgery.

Empyema GB in 29 patients (2.9\%), 6 cases of them (20.7\%) were converted to open surgery.

Small fibrosed GB with adhesions in 23 patients $(2.3 \%), 3$ cases $(13 \%)$ of them were converted to open surgery.

Totally frozen Calot's triangle in 17 patients (1.7), 6 cases (35.3\%) of them were converted to open surgery.

Choledochal cyst in 12 patients (1.2\%), 6 cases (50\%) of them were concerted, And double cystic duct in 23 patient $(2.3 \%), 6$ cases $(26.1 \%)$ of them were converted to open surgery.

That in agreement with other studies (Jeremy M et al., 2007; Al-Bahlooli et al., 2009; Muhammad et al., 2011; H. J. J et al., 2011; Hari Gopal et al., 2013; Gaharwar, 2013; Iqbal et al., 2013; Krishnanand \& Chanchlani, 2013; Chang et al., 2013).

Under such circumstances the decision to convert should be considered as a sign of surgical maturity rather than a failure and need to be taken at the time of recognition of a difficult dissection rather than after the occurrence of complications (Muhammad et al., 2011).

So we consider that as mature the surgeon as early he is brave to take the appropriate decision of transformation as regarded timing and adhesion. 
Regarding intraoperative complications we reported CBD injury in 16 cases (1.6\% of total), 6 cases of them $(37.5 \%)$ were converted to open surgery during the procedure (1.6\%) which was recognized immediately and 10 of them repaired laparoscopically with t-tube insertion.

Lipman et al., 2007 reported $0.5 \%$ CBD injury with transformation, 1.3\% CBD injury while Al-Bahlooli et al., 2009 reported $5 \%$ of CBD injury.

Also, we reported intraoperative bleeding that endanger patient life and to which transformation was lifesaving in two $(0.02 \%)$ patient while a bleeding that was controllable and accessible to be dealt with laparoscopically in 22 cases $(2.2 \%), 6$ cases $(27.2 \%$ of them) were converted to open surgery.

while Junaid Zaman and colleges from Pakistan in 2015 have found that Bleeding during postmortem of the gall bladder from the liver bed was the commonest finding i.e. 35.7\% (46 of 129 patients) followed by local adhesions $33.3 \%$ (43 of 129 patients) and perforation of gall bladder observed in 7.8\% (10 of 129 cases) (Zaman et al., 2015).

Sherma SK et al., 2007 in their study have noted the reasons for difficulties with more than $3 \mathrm{~mm}$ gall bladder wall thickness. They noticed $6 \%$ had dense adhesions around gall bladder, $0.2 \%$ had unclear anatomy of Calot's triangle even after dissection which runs very close to our results, $13.3 \%$ had bleeding from liver bed and $11.7 \%$ had perforation of gall bladder during peeling from liver bed (Sherma SK et al., 2007) which resembles out data obtained. However these can be overcome with experience of the surgeon.

Although we converted 43 (4.3\%) of 1005 patient from laparoscopic to open surgery other studies from near countries reported same or higher percentage of transformation.

Junaid Zaman et al., 2015 reported transformation rate was 10\% (13 out of 129 patients) which is similar to study performed by Majeski J. 2007 and Genc V. 2011.

Preoperative ultrasonographical prediction of a difficult laparoscopic cholecystectomy will not only help in patient counseling but also helps the surgeon to prepare better for intra operative risk and technical difficulties expected during surgery. Moreover, the patient safety may further be improved by seeking an expert advice (Zaman et al., 2015).

Also, Dhiraj Agarwal et al at Mahatma Gandhi Medical College and Hospital Jaipur studied 292 patients enrolled for laparoscopic cholecystectomy for three year and found that 26 patients $(8.9 \%)$ were converted to open surgery during all period of study from 72 (24.65\%) patient had difficult cholecystectomies.

Most of these transformations were due to inability to identify the anatomy so they did fundus first open Cholecystectomy or partial Cholecystectomy in these patients (Agarwal et al., 2016).

Regarding post-operative complications, we found that patients complained of post-operative complication as follow 962 case were not complicated ( $95.7 \%$ of total).

27 case among them $(0.28 \%)$ were converted to open surgery due to different reasons, bile leakage in 12 cases $(1.2 \%), 6$ cases $(50 \%)$ of them were been converted to open surgery and 6 cases completed and had postoperative bile leak.

Treatment vary from conservative to redo surgery and management according to finding, gallbladder fossa collection in 13 cases (1.3), all of them treated conservatively except one case that need ultrasound guided pig tail insertion.

Post-operative Jaundice occurred in 9 cases (0.9\%) 3 cases (33.3\%) had re-do surgery 2 cases that revealed CBD clipping and hepaticojejunostomy was done and one case found to have minor leak. while 6 cases of them needed ERCP and stent inserted.

Biliary peritonitis in 3 cases $(0.3 \%)$ none of them were converted but all the three needed re-do surgery for different caused that was treated accordingly, one of them died after one month due to peritonitis and septicemia, and wound infection in 6 cases $(0.6 \%) 3$ cases $(50 \%)$ of that cases reported to be converted at time of (LC).

Laparoscopic cholecystectomy had several Laparoscopic cholecystectomy had a several limitations and contraindications during the beginning of its functional introduction in medical operation. The surgeons were learning the system which was at the time as of late presented and it required some investment for specialists to build up the certainty and aptitude to perfom this task as a normal task. That time there was an unexpected ascent in the rate of normal bile channel (CBD) wounds and other intricacy. In spite of an enormous improvement in the technique, immense experience of the specialists, advanced instruments and anesthesia procedures, we still come across situations where one is faced with a technically difficult case. Among the common difficult cases include acute cholecystitis with adhesions, empyema gallbladder, distorted anatomy of Calot's triangle, congenital 
anomalies, electrocautery injury and many other similar conditions.

Our study focuses on the incidence of these difficult situations facing laparoscopic surgeons during laparoscopic cholecystectomy and how they deal with, also we focused on modalities of techniques that can be followed in each of them.

There are many other studies that features the significance of realizing when to stop the laparoscopic system and convert it to open procedure to maintain a strategic distance from hazardous difficults.

Transformation of the procedure is usually considered by vast majority of surgeons a failure of the procedure and with this thought in mind, surgeons make every effort to complete the procedure laparoscopically.

We emphasize the importance of transformation to open surgery when it is not possible to move any further with laparoscopic cholecystectomy as it can save the life of the patient we converted 43(4.27\%) of 1005 cases.

Our results show a very clear-cut increased incidence of operative and post-operative complications where procedure was continued despite obvious difficulties in dissection or sever bleeding that may endanger patient life.

Our main point of view is also supported by other studies emphasizing the importance of transformation when needed. One study mentioned the adverse effects of transformation like lengthening of the total operative time, post-operative morbidity and hospital expenses, but our perspective is the prevention of complications and safety of patients.

Our argument is also supported by a study stating that decision to transformation should focus on the safety of the patients instead of the length of operation or total cost incurred on procedure. Undue transformation is not advisable but should not be denied when patient's safety and life are under threat.

This study suggests that transformation of the laparoscopic cholecystectomy is not actually a failure of the surgeon, as is commonly interpreted, but is a lifesaving procedure as depicted by the results of the study. The experience of the operating surgeon plays a basic role in this regard.

Mortality occurred in 3 cases as a sequel of complications or due to infection, peritonitis and septicemia after more than 3 weeks of primary surgery so detailed data were not included.

\section{Conclusion}

Laparoscopic cholecystectomy is as much easy procedure as difficult one. Surgeon should consider every case as his first one. Intraoperative complications are common while transformation to open surgery should be always in consideration. Transformation to open cholecystectomy isn't a sign of lack of experience, rather it is a proof of surgeon cleverness and an evidence of professional competence as it could keep our patient away from life-threatening complications in difficult situations. Predictive factors for difficulty vary from male patient, repeated acute attacks, history of obstructive jaundice, presence of abnormal anatomical or pathological findings, and adhesions. bile duct damages may evaded even with nearness of hazard factors as anatomical variations from the of biliary channels, intense cholecystitis, extreme endless fibrosis, affected stones inside Hartmann pocket, and short cystic pipe during laparoscopic cholecystectomy by careful watching and wise decision of transformation whenever surgeon feels his patient is at risk of major complication in case of proceeding in laparoscopic technique. Mortality not encountered directly through the procedure or in short post-operative period but as sequel of complicated cases. Change of the laparoscopic cholecystectomy isn't really a disappointment of the specialist, as usually explained, yet is a lifesaving method as delineated by the results of the study. The experience of the operating surgeon assumes an essential function on this subject.

\section{Competing Interests Statement}

The authors declare that there are no competing or potential conflicts of interest.

\section{References}

Agarwal, D., Arora, D., Avasthi, A., Kothari, A., \& Dangayach, K. K. (2016). Study of 292 patients for prediction of difficult laparoscopic cholecystectomy using detailed history, clinical and radiological parameters. International Surgery Journal, 3(1), 349-353. https://doi.org/10.18203/2349-2902.isj20160258

Al-Bahlooli, S. H., Al-Malahi, A., Ghallab, N. H., Al-Dain, A. S., \& Al Sabahi, A. A.. (2009). Transformation rate of laparoscopic to open cholecystectomy. Yemeni journal for medical sciences, 1, 1-8.

Chang, Y. R., Jang, J. Y., Kwon, W., Park, J. W., Kang, M. J., Ryu, J. K., ... \& Kim, S. W. (2013). Changes in demographic features of gallstone disease: 30 years of surgically treated patients. Gut and liver, 7(6), 719. https://doi.org/10.5009/gnl.2013.7.6.719 
Corr, P., Tate, J. J., Lau, W. Y., Dawson, J. W., \& Li, A. K. (1994). Preoperative ultrasound to predict technical difficulties and complications of laparoscopic cholecystectomy. The American journal of surgery, 168(1), 54-56. https://doi.org/10.1016/S0002-9610(05)80071-6

Daradkeh, S. S., Suwan, Z., \& Abu-Khalaf, M. (1998). Preoperative ultrasonography and prediction of technical difficulties during laparoscopic cholecystectomy. World journal of surgery, 22(1), 75-77. https://doi.org/10.1007/s002689900352

Deitch, E. A. (1981). Utility and accuracy of ultrasonically measured gallbladder wall as a diagnostic criteria in biliary tract disease. Digestive diseases and sciences, 26(8), 686-693. https://doi.org/10.1007/BF01316856

Dubois, F., Icard, P., Berthelot, G. A., \& Levard, H. (1990). Coelioscopic cholecystectomy. Preliminary report of 36 cases. Annals of Surgery, 211(1), 60. https://doi.org/10.1097/00000658-199001000-00010

Gaharwar, A. (2013). Factors favouring cholelithiasis in North Indian population. IOSR J Pharmacy, 3(5), 01-3. https://doi.org/10.9790/3013-035101-03

Iqbal, P., Memon, A. A., Jamali, K. S., Shaikh, U., \& Qureshi, A. W. A. (2013). Laparoscopic Cholecystectomy; Peroperative factors responsible for difficulty in performance and conversion. Professional Med J, 20(3), 444-9.

Kassem, M. I., Elzeiny, M. M., El-Haddad, H. M., \& AbuNasr, A. A. (2015). Dome down approach for difficult laparoscopic cholecystectomy. The Egyptian Journal of Surgery, 34(3), 203. https://doi.org/10.4103/1110-1121.163152

Krishnanand, R. C., \& Chanchlani, M. (2013). Three port laparoscopic cholecystectomy in tertiary care hospital of central india-an audit of 200 patients. Journal of Evolution of Medical and Dental Sciences, 2, 8290-96. https://doi.org/10.14260/jemds/1455

Lengyel, B. I., Panizales, M. T., Steinberg, J., Ashley, S. W., \& Tavakkoli, A. (2012). Laparoscopic cholecystectomy: What is the price of conversion?. Surgery, 152(2), 173-178. https://doi.org/10.1016/j.surg.2012.02.016

Lipman, J. M., Claridge, J. A., Haridas, M., Martin, M. D., Yao, D. C., Grimes, K. L., \& Malangoni, M. A. (2007). Preoperative findings predict conversion from laparoscopic to open cholecystectomy. Surgery, 142(4), 556-565. https://doi.org/10.1016/j.surg.2007.07.010

Martin, I. G., Dexter, S. P. L., Marton, J., Gibson, J., Asker, J., Firullo, A., \& McMahon, M. J. (1995). Fundus-first laparoscopic cholecystectomy. Surgical endoscopy, 9(2), 203-206. https://doi.org/10.1007/BF00191967

Medeiros, A. C., Araújo-Filho, I., Carvalho, M. D. F., de Paiva Medeiros, V. F. L., de Azevedo, Í. M., \& Dantas Filho, A. M. (2012). Laparoscopic versus open cholecystectomy: Complications and cost. Journal of Surgical and Clinical Research, 3(2), 49-58. https://doi.org/10.20398/jscr.v3i2.3567

Merriam, L. T., Kanaan, S. A., Dawes, L. G., Angelos, P., Prystowsky, J. B., Rege, R. V., \& Joehl, R. J. (1999). Gangrenous cholecystitis: analysis of risk factors and experience with laparoscopic cholecystectomy. Surgery, 126(4), 680-686. https://doi.org/10.1016/S0039-6060(99)70122-4

Muhammad, R. M., Ghulam, M., Saima, A., Muhammad, A. J., Ali, G. B., \& Syed, Q. A. S. (2011). Study of open transformation in laparoscopic cholecystectomy. Gomal Journal of Medical Sciences, 9, 51-54.

Murayama, K. M., \& Thompson, J. S. (1996). Retrograde laparoscopic gallbladder dissection. Contemp Surg, 48, 106-107.

Ralls, P. W., Quinn, M. F., Juttner, H. U., Halls, J. M., \& Boswell, W. D. (1981). Gallbladder wall thickening: patients without intrinsic gallbladder disease. American Journal of Roentgenology, 137(1), 65-68. https://doi.org/10.2214/ajr.137.1.65

Ranjith, R. M., Sunil, K. M., \& Sathyanarayana, N. (2015). Pre-Operative ERCP Is a Significant Difficulty Predictor for Laparoscopic Cholecystectomy - An Analysis. OSR-JDMS, 14(7), 64-69. Retrieved from www.iosrjournals.org

Russell, J. C., Walsh, S. J., Reed-Fourquet, L., Mattie, A., \& Lynch, J. (1998). Symptomatic cholelithiasis: a different disease in men? Connecticut Laparoscopic Cholesystectomy Registry. Annals of surgery, 227(2), 195. https://doi.org/10.1097/00000658-199802000-00007

Selmani, R., \& Karpuzi, A. (2013). The Enormous Size of the Gallblader-A Reason for Conversion to Open Surgery in Acute Cholecystitis. Global Journal of Medical Research. 
Sultan, A. M., El Nakeeb, A., Elshehawy, T., Elhemmaly, M., Elhanafy, E., \& Atef, E. (2013). Risk factors for conversion during laparoscopic cholecystectomy: retrospective analysis of ten years' experience at a single tertiary referral centre. Digestive surgery, 30(1), 51-55. https://doi.org/10.1159/000347164

Taha, B. (2016). Acute Cholecystitis best timing of Laparoscopic Cholecystectomy. IJMRD, 3(8), 281-285. Retrieved from www.allsubjectjournal.com.

Vyas, H. G., Bhandari, V., Saurabh, P. T., \& Singh, M. (2013). pre-operative predictors of difficult laparoscopic cholecystectomy; comparisons of two scoring systems. A single center prospective study. Journal of Evolution of Medical and Dental Sciences, 2(41), 7855-7862. https://doi.org/10.14260/jemds/1386

Yol, S., Kartal, A., Vatansev, C., Aksoy, F., \& Toy, H. (2006). Sex as a factor in conversion from laparoscopic cholecystectomy to open surgery. JSLS: Journal of the Society of Laparoendoscopic Surgeons, 10(3), 359.

Zaman, J., Imaduddin, S., \& Razzak, R. (2015). Frequency of difficult laparoscopic cholecystectomy in patients with thick walled gall bladder. Pak J Surg, 31(3), 165-168.

\section{Copyrights}

Copyright for this article is retained by the author(s), with first publication rights granted to the journal.

This is an open-access article distributed under the terms and conditions of the Creative Commons Attribution license (http://creativecommons.org/licenses/by/4.0/). 